\title{
Effect of decalcification agents on immunoreactivity of cellular antigens
}

\author{
N A ATHANASOU, J QUinN, A HERYET, C G WOODS,* J O’D McGeE \\ From the University of Oxford, Nuffield Department of Pathology, John Radcliffe Hospital, Oxford, and \\ * Nuffield Orthopaedic Centre, Headington, Oxford
}

SUMMARY The effects of several strong acids, weak acids, a proprietary decalcifier, and edetic acid on the immunohistochemical staining of cryostat and faed paraffin embedded sections of tissue from a variety of normal and pathological calcified and uncalcified specimens were studied. Even decalcification in strong acids $\left(\mathrm{HCl}, \mathrm{HNO}_{3}, 5 \%\right.$ trichloracetic acid, $\mathrm{HCl}$-edetic acid did not diminish the reactivity of many useful antigens (including leucocyte common antigen, intermediate filaments, S100 protein and epithelial membrane antigen). Weaker acids (formic acid, acetic acid) and edetic acid decalcified more slowly and generally showed greater preservation of antigenic reactivity with better morphology and staining quality. Trichloracetic acid was also useful as a quick one step fixation and decalcifying agent for both cryostat and routinely processed sections. Knowledge of the preservation of antigenic reactivity in decalcified tissue will be useful in the diagnosis of tumours of uncertain histogenesis and origin which affect calcified tissues.

Immunohistochemical analysis of surgical specimens using monoclonal antibodies has assumed an important role in histopathological diagnosis. Although frozen material and cryostat sections are optimal for the preservation of the reactivity of many antigens, routine formalin fixation and paraffin embedding, often associated with protease digestion of tissue sections prior to immunostaining, has been found to interfere only partially with the localisation of many cellular and tissue antigens useful in tissue diagnosis. ${ }^{1-3}$ With calified tissues, the situation is more complex as fixation is generally followed by a decalcification procedure. Although there are several decalifying agents in common use, their effect on the immunoreactivity of the various cellular and tissue antigens has been little studied. ${ }^{45}$ This is often of particular importance where panels of monoclonal antibodies are used in the histopathological diagnosis of tumours of uncertain origin. ${ }^{6}$

In this study we examined the effect of several decalcifying agents, including strong acids, weak acids, and chelating agents on immunohistochemical staining for several diagnostically useful cellular and tissue antigens in both calcified and uncalcified surgical specimens.

Accepted for publication 19 March 1987

\section{Material and methods}

Surgical specimens included normal appendix, thyroid, skin, breast, prostate, bone, and tonsil, as well as cases of carcinoma (lung, kidney), myeloma, and lymphoma affecting bone. Table 1 shows the antigenic determinants sought in each of these tissues.

The tissues were either snap frozen in liquid nitrogen for cryostat sectioning or fixed in $10 \%$ formol saline at room temperature for a minimum of 24 hours (range 24 hours-14 days). Slices of the fixed tissues were then routinely processed to paraffin wax. A parallel fixed slice was also placed in one of several decalcifying agents for 24 hours and three days. The agents studied were $5 \%$ aqueous nitric acid $\left(\mathrm{HNO}_{3}\right)$, $5 \%$ aqueous hydrochloric acid $(\mathrm{HCl}), 10 \% \mathrm{RD} 0$ (Bethlehem, Gotheberg), 5\% trichloracetic acid (TCA), $10 \%$ aqueous formic acid (FA), $10 \%$ aqueous acetic acid (AA), and 10\% $\mathrm{HCl}$-edetic acid (ethylene diaminetetracetic acid) mixture. Specimens were also decalcified in edetic acid alone ( 24 hours and seven days), as well as being solely fixed and decalcified in TCA for 24 hours. After washing in running tap water for four to six hours the treated specimens were processed via ethanol (six hours) and xylene (three hours) to paraffin wax. Five micron sections were mounted on Multispot slides (Hendley, Essex) and dried at $60^{\circ} \mathrm{C}$ for 60 minutes. Before immunostaining, all paraffin sections were dewaxed in xylene and 
Table 1 Antigenic determinants sought in surgical specimens examined

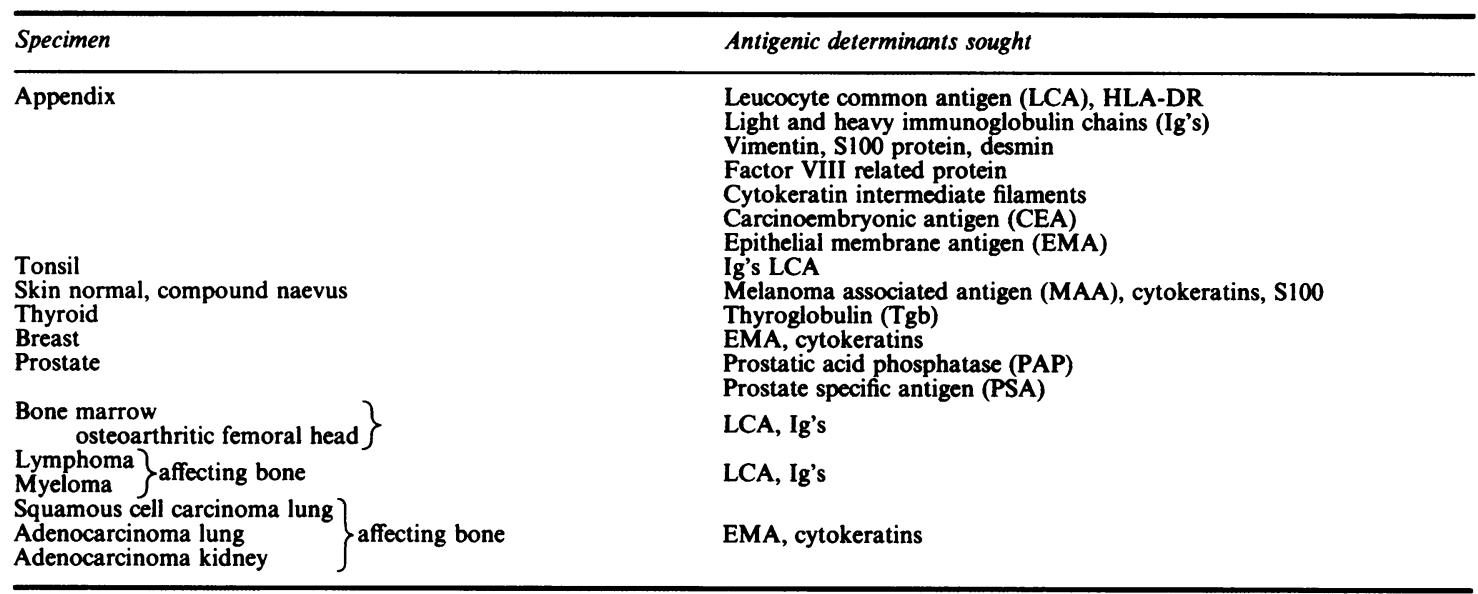

rehydrated through graded alcohols to water. Parallel slices of appendix were also processed to cryostat sections after fixation and decalcification ( 24 hours) in the various agents, as noted above, to assess if specimens could be rapidly fixed and decalcified without destroying antigen reactivity.

Table 2 gives details of monoclonal antibodies used in this study. Polyclonal rabbit antibodies against human immunoglobulin heavy and light chains (Ig), thyroglobulin, and prostate specific antigen (PSA) were obtained from Dako (UK) and antiprostatic acid phosphatase (PAP) from Miles Scientific Ltd. Immunohistochemistry was performed using an indirect immunoperoxidase or alkaline phosphatase antialkaline phosphatase (APAAP) procedure, as previously described. ${ }^{17}$ Both control and decalcified sections of fixed tissue were digested by $0.1 \%$ trypsin (Sigma T: 8128 ) in $0.1 \%$ calcium chloride at $\mathrm{pH} \mathrm{7.8}$ before immunostaining with the following antibodies: CR3/43, anti-light chain Ig, anti-heavy chain Ig, anticarcinoembryonic antigen, anti-PSA, anti-PAP, anti$\mathrm{Tgb}$, and anti-factor VIII related antigen (30 minutes); CAM 5.2 (15 minutes); DER-11 (20 minutes). The histological quality, degree, and specificity of immunohistochemical staining was scored relative to that of fixed undecalcified control sections.

\section{Results}

Table 3 summarises the effect on the immunoreactivity of cellular antigens after treatment with the various decalcifying agents (figs 1 and 2). Prolonged (three day) decalcification produced no noticeable differences in terms of antigen reactivity or antibody specificity but had an effect on morphology and stain-
Table 2 Monoclonal and polyclonal* antibodies used for analysis of routinely processed decalcified tissues

\begin{tabular}{|c|c|}
\hline Antibody & Antigenic determinant \\
\hline 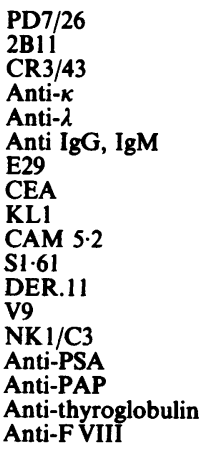 & $\begin{array}{l}\text { Leucocyte common antigen } \\
\text { Leucocyte common antigen } \\
\text { HLA-DR }^{8} \\
\text { Light and heavy immunological chains } \\
\text { Epithelial membrane antigen } \\
\text { Carcinoembryonic antigen }^{10} \\
\text { Cytokeratin intermediate filaments } \\
\text { Cytokeratin intermediate filaments }^{12} \\
\text { S100 protein }^{13} \\
\text { Desmin }^{14} \\
\text { Vimentin } \\
\text { Melanoma associated antigen } \\
\text { Prostate specific antigen } \\
\text { Prostatic acid phosphatase* } \\
\text { Thyroglobulin } \\
\text { Factor VIII related antigen }\end{array}$ \\
\hline
\end{tabular}

*Indicates polyclonal antibodies.

ing quality. Undecalcified controls that were processed to cryostat sections of formalin fixed paraffin embedded sections were all strongly positive with the antibodies tested.

Treatment with the strong acids $\mathrm{HCl}$ and $\mathrm{HNO}_{3}$ and the proprietary decalcifier RD0 for 24 hours and three days preserved immunoreactivity of all antigens tested with the exception of HLA-DR and epithelial membrane antigen (EMA). Tissue morphology and staining quality was adversely affected, particularly after prolonged (three day) decalcification, but immunostaining was still interpretable. $\mathrm{HCl}$-edetic acid treatment was associated with better morphology and weak EMA reactivity was retained. TCA treatment (both with and without prior formalin 
Table 3 Effect of decalcifying agents on immunoreactivity of tissue antigens*

\begin{tabular}{|c|c|c|c|c|c|c|c|c|c|}
\hline $\begin{array}{l}\text { Antigenic } \\
\text { determinant }\end{array}$ & $\begin{array}{l}\text { Undecalcified } \\
\text { control }\end{array}$ & $\mathrm{HCl}$ & $\mathrm{HNO}_{3}$ & $R D O$ & $\begin{array}{l}\mathrm{HCl}- \\
\text { edetic acid }\end{array}$ & TCA† & $A A$ & $F A$ & Edetic acid $\ddagger$ \\
\hline $\begin{array}{l}\text { LCA } \\
\text { HLA-DR } \\
\text { Light Ig chain } \\
\text { Heavy Ig chain } \\
\text { Cytokeratins } \\
\text { CEA } \\
\text { Vimentin } \\
\text { S100 protein } \\
\text { F VIII } \\
\text { MAA } \\
\text { PAP } \\
\text { PAA } \\
\text { Tgb } \\
\text { Desmin } \\
\text { EMA }\end{array}$ & 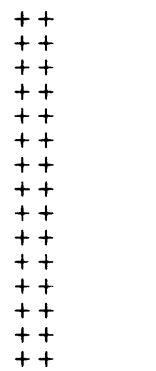 & $\begin{array}{l}+t \\
+ \\
+ \\
++ \\
+ \\
+ \\
+ \\
+ \\
++ \\
+t \\
++ \\
++\end{array}$ & $\begin{array}{l}++ \\
+ \\
+ \\
++ \\
+ \\
+ \\
+ \\
+ \\
++ \\
++ \\
++ \\
++ \\
+\end{array}$ & $\begin{array}{l}+t \\
+ \\
+ \\
+t \\
+ \\
+ \\
+ \\
+ \\
++ \\
+t \\
+t \\
+ \\
t\end{array}$ & 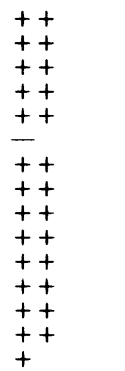 & $\begin{array}{l}+t \\
++ \\
++ \\
++ \\
++ \\
+t \\
++ \\
++ \\
+t \\
++ \\
++ \\
++ \\
++\end{array}$ & $\begin{array}{l}++ \\
++ \\
++ \\
++ \\
+t \\
++ \\
+t \\
++ \\
+t \\
+t \\
+t \\
+t \\
++ \\
+t \\
+t\end{array}$ & $\begin{array}{l}++ \\
++ \\
++ \\
++ \\
++ \\
++ \\
++ \\
++ \\
++ \\
++ \\
++ \\
++ \\
++ \\
++ \\
++\end{array}$ & $\begin{array}{l}++ \\
++ \\
++ \\
++ \\
++ \\
++ \\
++ \\
++ \\
++ \\
++ \\
++ \\
++ \\
++ \\
++ \\
++\end{array}$ \\
\hline
\end{tabular}

*Each tissue was decalcified for 24 hours and 3 days: the results were similar for both time periods. $++=$ strong staining; $+=$ weak staining.

†With and without formalin pre-fixation. $\ddagger$ Also seven days of edetic acid decalcification.

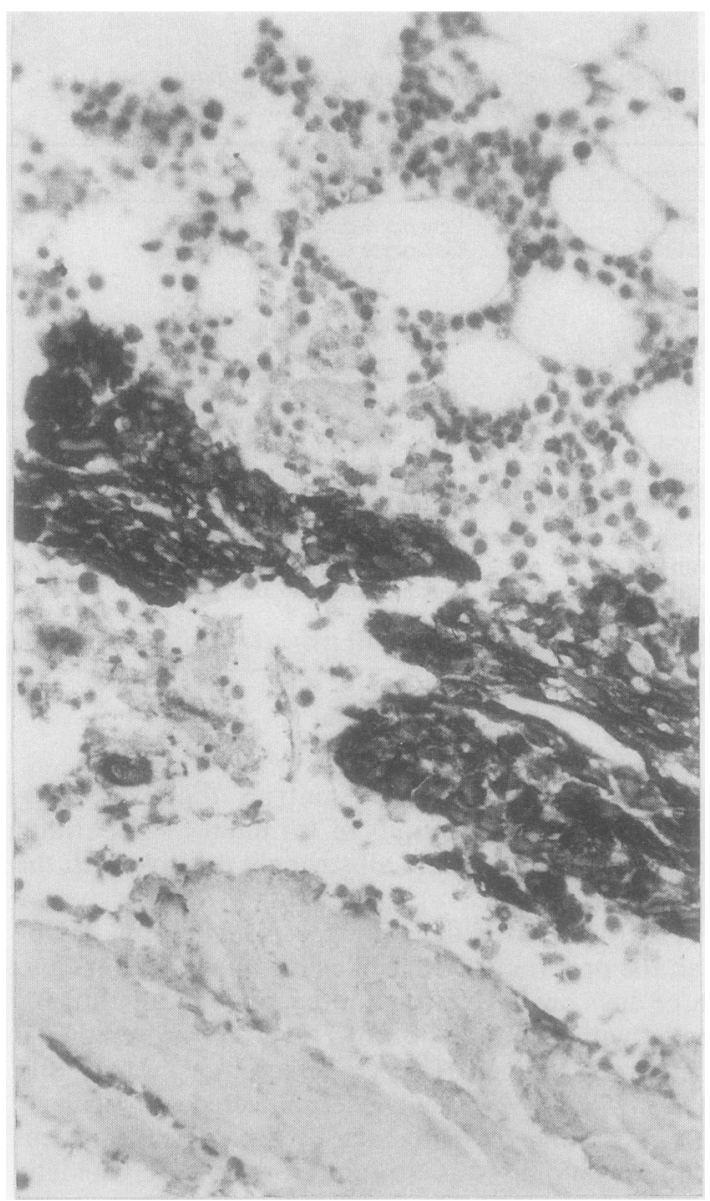

Fig 1 Squamous cell carcinoma of lung infiltrating bone: tumour cells are stained for cytokeratin intermediate filaments (CAM 5.2). (Immunoperoxidase, decalcification HCl-edetic acid 24 hours).

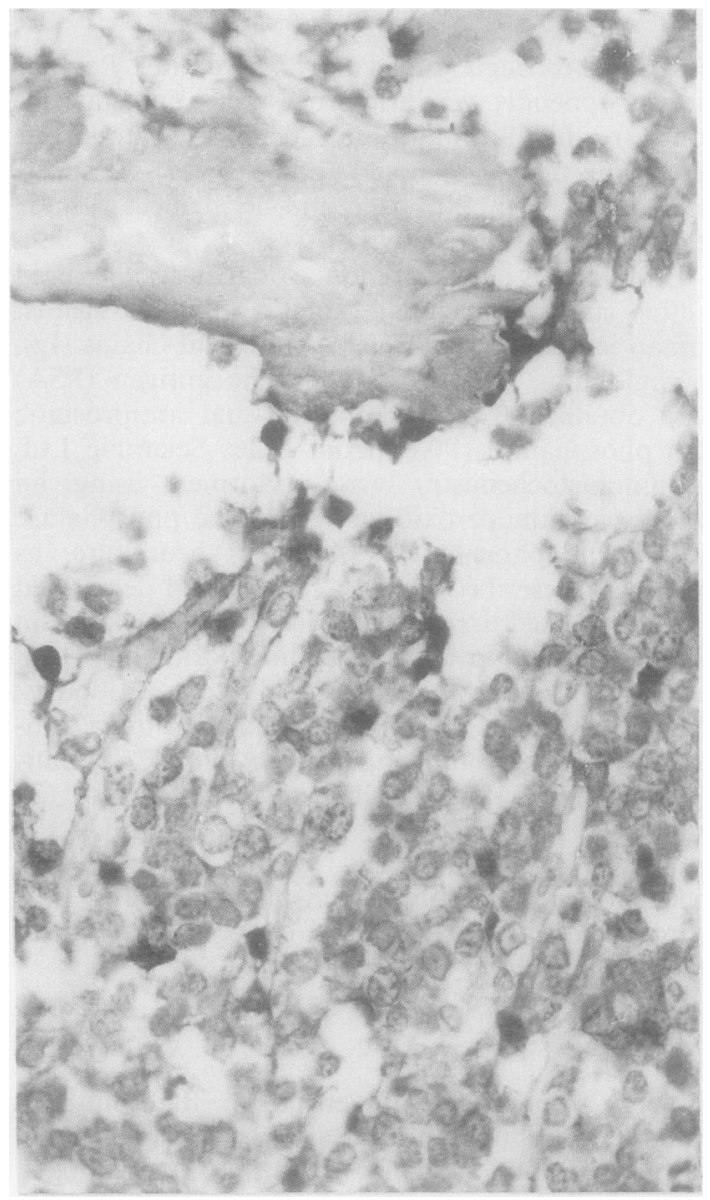

Fig 2 Lymphoma infiltrating bone (right) with tumour cells showing membrane staining for leucocyte common antigen (PD7/26). (Immunoperoxidase, decalcification TCA 24 hours). 
fixation) also showed good staining quality and preservation of both morphology and antigenic reactivity. No particular advantage in terms of immunohistochemistry was found in using the proprietary decalcifier (RD0) tested. It should also be noted that, although both anti-leucocyte common antigen antibodies tested, PD7/26 and 2B11, reacted with leucocytes after 24 hours in all decalcifying agents, 2B11 did not react with leucocytes after three days of decalcification in $\mathrm{HCl}, \mathrm{HNO}_{3}, \mathrm{RDO}$ and TCA.

Treatment with weak acids (FA, AA) and edetic for 24 hours and three days showed generally better staining quality and morphology in tissue sections, with preservation of the reactivity of most antigens tested. Decalcification of the bone specimens affected by tumour, however, was rarely complete after 24 hours and often still incomplete after three days.

To determine if tissues could be rapidly fixed and decalcified without destroying antigen reactivity and cell morphology cryostat sections of parallel slices of appendix were cut after fixation and decalcification for 24 hours in the agents listed (edetic acid, a slow decalcifying agent, excepted). Antigenic reactivity in cryostat sections was similar to that seen in the correspondingly decalcified routinely processed paraffin embedded sections. In addition, cryostat sections of TCA fixed and decalcified specimens of bone and appendix showed a similar pattern of antibody staining to that seen in material embedded in paraffin and previously treated with TCA. This indicates that TCA could be useful as a rapid one step fixation and decalcification agent for both cryostat and routinely processed sections. In immunoperoxidase stained cryostat sections background staining of red cells was strong with all decalcifying agents, even after blocking with methanol- $\mathrm{H}_{2} \mathrm{O}_{2}$, and could potentially cause difficulty in interpretation. Background staining of red cells was also seen in immunoperoxidase stained paraffin sections but was not as pronounced. This effect was avoided by use of the APAAP technique.

\section{Discussion}

The selection of an appropriate decalcifying agent is largely governed by two factors: the amount of mineralised tissue present in the specimen; and the urgency of the specimen requiring decalcification. Subsequent staining and investigative procedures, which may need to be carried out on the decalcified specimen, are also important, however, and it is this last factor that we examined with respect to immunohistochemistry.

Even the most common rapid decalcification procedure in general use - that is, strong acids such as $\mathrm{HCl}, \mathrm{HNO}_{3}$ - did not lessen the reactivity of many diagnostically useful antigenic determinants. Cytological detail and staining quality were adversely affected, particularly after prolonged decalcification in strong acids. Interpretation of immunohistochemical staining, however, was still clear, and most specimen blocks of bone should be decalcified within 24 hours in the above solutions. $\mathrm{HCl}$-edetic acid also provided rapid decalcification with excellent morphology and good preservation of antigenic reactivity.

Treatment with TCA was useful as it provided a rapid one step fixation and decalcification procedure that led to retention of many useful antigenic components, as well as excellent morphology and staining quality. TCA decalcification was also suitable for use with cryostat and paraffin sections, allowing a quick tissue diagnosis to be obtained. Treatment with weak acids and edetic acid undoubtedly resulted in better morphological detail and staining quality, with greater retention of antigenic reactivity. These agents, however, are not suitable for urgent or larger specimens as decalcification of the bone specimens was often not complete within 24 hours.

Recognition of antigenic determinants in the decalcified specimens by the polyclonal and monoclonal antibodies studied should aid in the histological diagnosis of tumours of uncertain histogenesis and origin that affect calcified tissues. ${ }^{4}$ Antigenic determinants for tumours of lymphoid or haemopoietic (leucocyte common antigen, light and heavy immunoglobulin chain), epithelial (cytokeratins, epithelial membrane antigen), mesenchymal (vimentin, desmin, factor VIII related antigen), or other (MAA, S100) differentiation can be distinguished, even in specimens decalcified in strong acid solutions. In addition, antigenic components of tumours likely to metastasise to bone such as PSA, PAP-prostate, ${ }^{16} 17$ Tgb-thyroid, ${ }^{18}$ Carcinoembryonic antigen large bowel cancer ${ }^{10}$ can be recognised in decalcified tissue if the appropriate decalcifying agent is used. Knowledge of the effects of the various decalcifying agents on the immunoreactivity of cellular antigens should rationalise prospective and retrospective immunohistochemical analysis of tumours in calcified tissue.

This work was supported by a grant from the Arthritis and Rheumatism Council. We thank Miss L Watts for typing the manuscript and $\mathrm{Mr} \mathrm{J}$ Markham for photographic assistance.

\footnotetext{
References

1 Taylor CR. Immunoperoxidase techniques: practical and theoretical aspects. Arch Pathol Lab Med 1978;102:113-22.

2 Heyderman E. Immunoperoxidase technique in histopathology: applications, methods and controls. J Clin Pathol 1979;32: 971-8.

3 Curran RC, Gregory J. The unmasking of antigens in paraffin sections of tissue by trypsin. Experientia 1977;33:1400-1.

4 Matthews JB. Influence of decalcification on immuno-
} 
histochemical staining of formalin-fixed paraffin embedded tissue. J Clin Pathol 1982;35:1392-4.

5 Mukai K, Yoshimura MT, Anzar MT. Effects of decalcification on immunoperoxidase staining. Am $J$ Surg Pathol 1986;10:413-9.

6 Gatter KC, Abdulaziz Z, Beverley P, et al. Use of monoclonal antibodies for the histopathological diagnosis of human malignancy. J Clin Pathol 1982;35:1253-67.

7 Warnke RA, Gatter KC, Falini B, et al. Diagnosis of human lyniphoma with monoclonal antileukocyte antibodies. $N$ Engl $J$ Med 1983;309:1275-81.

8 Naiem M, Gerdes J, Abudlaziz Z, Nash J, Stein H, Mason DY. Production of monoclonal antibodies for the immunohistological analysis of human lymphoma. In: Knapp W, et al, eds. Leukaemia markers. New York: Academic Press, 1981:117-25.

9 Cordell J, Richardson TC, Pulford KAF, et al. Production of two monoclonal antibodies against human mammary epithelial membrane antigens and their use in diagnostic immunochemistry. Br J Cancer 1985;52:347-54.

10 Heydermann E, Neville AM. A shorter immunoperoxidase technique for the demonstration of carcinoembryonic antigen and other cell products. J Clin Pathol 1979;30:138-40.

11 Viac J, Reano A, Brochier J, et al. Reactivity pattern of a monoclonal antikeratin antibody (KL1). $J$ Invest Dermatol 1981;81:351-4.

12 Makin CA, Bobrow LG, Bodmer WF. Monoclonal antibody to cyotkeratin for use in routine histopathology. J Clin Pathol 1984;37:975-83.

13 Vanstapel MJ, Peeters B, Cordell J, et al. Production and identification of monoclonal antibodies directed against an antigenic determinant common to the alpha and beta chain of S100. Lab Invest 1985;52:232-8.

14 Debus E, Weber K, Osborn M. Monoclonal antibodies to desmin the muscle specific intermediate filament protein. EMBO J 1983;2:2305-9.

15 Altmannsberger M, Osborn M, Schauer A, Weber K. Antibodies to different intermediate filament proteins: cell type specific markers on paraffin embedded human tissues. Lab Invest 1981;45:427-34.

16 Mackie RM, Campbell I, Turbitt ML. Use of NK1 C3 monoclonal antibody in the assessment of benign and malignant melanocytic lesions. J Clin Pathol 1984;37:367-72.

17 Gatter KC, Falini B, Mason DY. The use of monoclonal antibodies in histopathological diagnosis. In: Anthony $\mathrm{P}$, MacSween $\mathrm{R}$, eds. Recent advances in histopathology. Edinburgh: Churchill Livingstone, 1984:35-67.

18 Jobsis AC, De Vries GP, Arholt RRH, Sanders GTB. Demonstration of the prostatic origin of metastases. An immunohistological method for formalin-fixed embedded tissue. Cancer 1978;41:1788-93.

19 Wang MC, Papsidero L, Muryama M, et al. Prostate antigen: a new potential marker for prostatic cancer. The Prostate 1981;2:89-96.

20 Burt A, Goudie RB. Diagnosis of primary thyroid carcinoma by immunohistological demonstration of thryoglobulin. Histopathology 1979;3:279-86.

Requests for reprints to: $\mathrm{Dr} \mathbf{N}$ Athanasou, Nuffield Department of Pathology, John Radcliffe Hospital, Headington, Oxford OX3 9DU, England. 